\title{
physiokongress
}

24.-26. Januar 2014

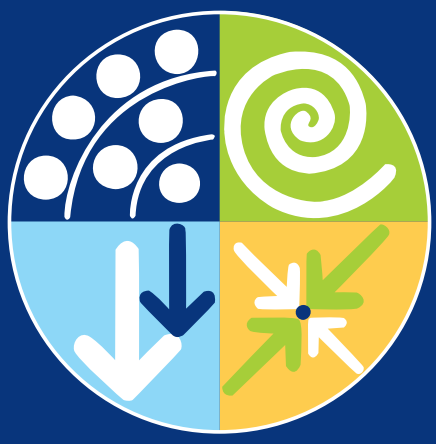

\section{Altersschwach war gestern}

PHYSIOKONGRESS 2014: DER SAMSTAG Eine moderne, evidenzbasierte

Phyisotherapie kann Gebrechlichkeit verhindern. Das zeigen die Referenten

auf Thiemes physiokongress am Samstag. Außerdem: Ein Update zum

Thema Faszienforschung.

Junge Programme für alte Menschen, Teil 1

11.30 Uhr-13 Uhr

Diesen Block eröffnet Prof. Dr. Clemens Becker, Chefarzt der Klinik für Geriatrische Rehabilitation am Robert-Bosch-Krankenhaus Stuttgart. Sein Thema: „Dem Sensenmann davonlaufen“.

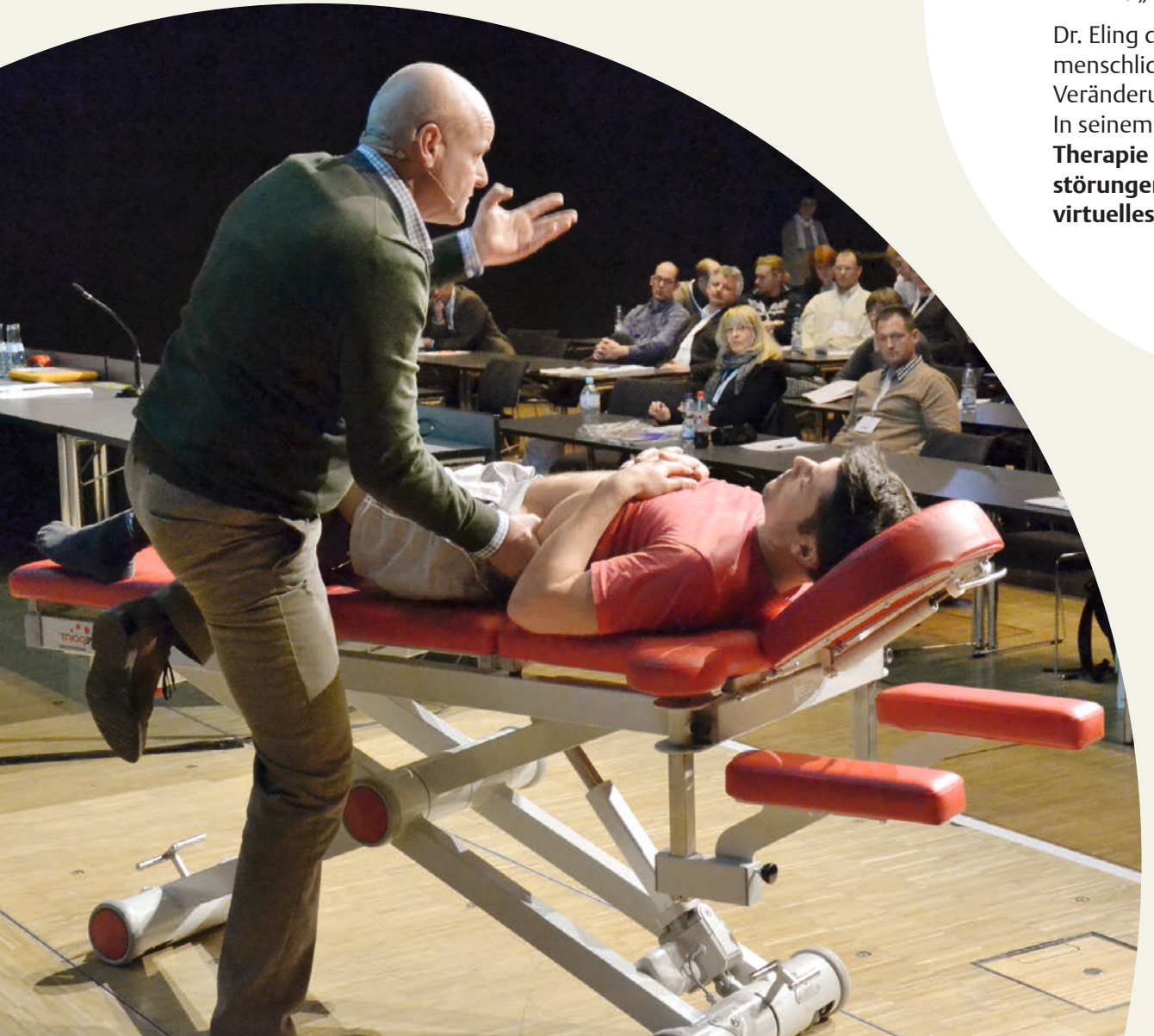




\section{Keynote-Vorträge: Faszien}

9 Uhr-10.30 Uhr

Dr. Robert Schleip, Wissenschaftler von der Fascia Research Group der Universität Ulm, spricht im ersten Keynote-Vortrag zum Thema „Faszination Faszien“ und berichtet über die neuesten Erkenntnisse in der Faszienforschung.

Christopher Gordon, Physiotherapeut und Osteopath aus Stuttgart, forscht ebenfalls in Ulm. Im zweiten Keynote-Vortrag referiert er über den Transfer von myofaszialer Wissenschaft zur evidenzbasierten Physiotherapie.

Die Keynote-Vorträge finden gemeinsam mit dem Süddeutschen Symposium des VPT statt.

\section{Junge Programme für} alte Menschen, Teil 2

\section{Uhr -18.30 Uhr}

Lutz Schwickert, Diplom-Sportwissenschaftler an der Klinik für Geriatrische Rehabilitation des Robert-Bosch-Krankenhauses Stuttgart, hat das Thema Robotiktherapie nach Schulterverletzungen.

Dr. Wolfgang Laube ist Arzt für Physikalische Medizin. Er referiert zu Koordination und Kraft im Alter - Charakteristika des Gesundheitsstatus.

\section{Den Einfluss von Wirbelsäulenschmerz, Statik} und Beweglichkeit auf das Sturzrisiko erklärt Antonia Diegisser, Physiotherapeutin und wissenschaftliche Mitarbeiterin an der Universitätsmedizin der Johannes Gutenberg-Universität Mainz.

\section{THERAPRO 2014}

Junge Programme für alte Menschen, Teil 3

\subsection{Uhr - 17 Uhr}

Fördern körperlicher Aktivität älterer Menschen durch Informations- und Kommunikationstechnik - Wunschdenken oder bald Realität? Diese Frage beantwortet Prof. Dr. Wiebren Zijlstra, Professor am Institut für Bewegungs- und Sportgerontologie der Deutschen Sporthochschule Köln.

Karin Kampe, Diplom-Sportwissenschaftlerin an der Klinik für Geriatrische Rehabilitation des Robert-Bosch-Krankenhauses in Stuttgart, spricht anschließend über „Otago - ein aktives Übungsprogramm“.

\section{Infos und Anmeldung}

Thiemes physiokongress 2014 findet im Rahmen der Messe TheraPro statt, der größten Messe für Therapieberufe in Süddeutschland. Auf dieser Messe können sich Physiotherapeuten, Ergotherapeuten, Osteopathen und Masseure über Aktuelles aus der Branche und neue Produkte informieren. Da zwischen den Vortragsblöcken des physiokongresses immer genügend Zeit eingeplant ist, bietet die Messe auch eine optimale Plattform, um sich mit anderen Therapeuten auszutauschen.

Mehr zum Programm des physiokongresses finden Sie unter www.thieme.de/physiokongress und in den Ausgaben 10/2013 sowie $1 / 2014$ von physiopraxis. Über die TheraPro können Sie sich informieren unter www.therapro-messe.de.

\section{Übrigens: physiopraxis-Abonnenten und Besucher des physiokongresses 2013 erhalten einen ermäßigten Eintrittspreis!}

